robots range widely from helpful house servants to agents on planetary missions. But my greatest enjoyment came from the end of the book, which is more philosophical. Brooks' philosophy is blunt: abilities that some hold dear as being specially human (for example, emotions and consciousness) are available to machines simply because humans are machines, albeit immensely complex ones.

He prepares a robust response to potential attacks by detractors who believe that the 'specialness' of human consciousness either lies in an as yet uncomprehended presence of quantum physical action in the brain, or is not available to physics at all. $\mathrm{He}$ accuses some philosophers of simply being afraid to contemplate the possibility of a conscious machine. According to Brooks, the adversaries will have to prove their points or admit that humans can be understood from physical control principles. Despite this, Brooks has his own little je ne sais quoi which separates the biological from the artefactual. The 'juice', as he calls it, that is missing is a proper mathematical understanding of complex biological mechanisms. He does not see this as an insurmountable difficulty, but rather as an achievable and exciting target for science.

The second book, The Body Electric, is a clear and readable report of the way that human sensory systems are being replaced or supplemented by technological artefacts studied in a variety of research laboratories across the world. Journalist James Geary tells an exciting story not only by reporting his in-depth interviews with key researchers, but also by asking the beneficiaries of some prostheses what this has done for them. People who have seen, heard and learned to speak for the first time are the best ambassadors for this science - their accounts detract from any false impression that humanity is being insidiously invaded by the silicon chip.

Inevitably, reportage can fall prey to some odd views held by those who are being interviewed. A British engineer, for example, insists that a radio chip he had implanted under the skin of his forearm to open doors and cause his computer to greet him is a major step towards the automatic transmission of emotions and, eventually, thoughts, between humans. Here the scientific challenges of encoding thought and emotion distributed over billions of brain cells are suspended, and would a chip in the pocket not have opened the door just as well?

By contrast, the rest of the book presents real scientific work on vision, hearing, touch and even taste. The question is always the same: how can a sensory faculty be restored to an individual who may have lost it? Often this needs an enormous amount of ingenuity, mainly because the human brain is adept at integrating the input from many sensory modalities. For example, in order to 'see', the brain integrates signals from the retina with signals from the oculomotor system that moves the eyes. The key question is whether what's left of the brain's apparatus when parts go missing will be able to accept and adapt to the retinal implant in order to bring to the perceptual mind some sense of seeing. Geary answers this by sharing the delight of a 63-year-old Belgian woman who, after having been blind for over 20 years, began to see dots of colours when her optic nerve was stimulated by the output of a small video camera.

Having dealt with the senses, Geary approaches the problem of artificial minds. He talks to some who insist that they can create a mind just by throwing neural networks together and letting the mind emerge, as well as to others who have more principled approaches along the lines of the work reviewed by Brooks. Geary, rightly, just reports, and leaves it to the reader to spot the outliers.

Igor Aleksander is in the Intelligent and Interactive Systems Group, Department of Electrical and Electronic Engineering, Imperial College of Science Technology and Medicine, London SW7 2BT, UK.

\section{Putting evolution in context}

The Alfred Russel Wallace Reader A Selection of Writings from the Field

edited by Jane Camerini

Johns Hopkins University Press: 2002. 248 pp.

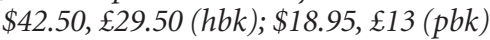

Infinite Tropics: An Alfred Russel

Wallace Anthology

edited by Andrew Berry

Verso: 2002. 320 pp. $£ 19, \$ 27$

\section{Charlotte Sleigh}

Charles Darwin kept many of his opinions, especially on politics and religion, under his hat. As a result, biologists, historians, marxists, keynesians, atheists and fundamentalists have all enjoyed debating ever since what Darwin 'really' meant. This kind of parlour game is no fun with Alfred Russel Wallace. A far more colourful and opinionated Victorian, he promulgated his beliefs to anyone who would listen. Ranging through socialism, geography, exobiology, phylogeny, female suffrage, natural selection, land reform and spiritualism, his sheer breadth of interests creates a challenge for the anthologist: how to group his writings to give the truest impression of his life and work.

This is a healthy challenge. Darwin's silence on contentious issues has obstructed a truly historicized understanding of his natural history, suggesting to some that the

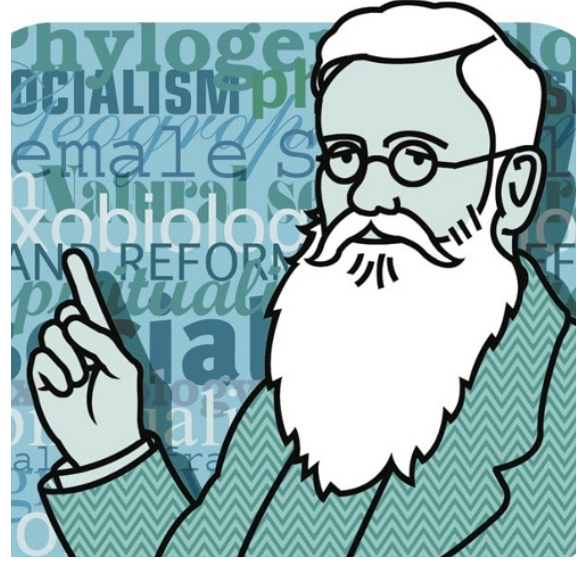

theory of evolution may be understood (could, even, have been created) in isolation from its social milieu. Wallace allows no such facile judgements. How should we appreciate the remarkable practical and theoretical achievements of this man, knowing that he promoted table-tapping and utopian community with equal seriousness and fervour?

Stephen Jay Gould, in his preface to Andrew Berry's Infinite Tropics, appears somewhat unnerved by this paradox, referring uncomfortably to Wallace's "promiscuous... outpourings" of non-scientific writing. Berry responds to the challenge by grouping Wallace's writings thematically, while recognizing that this artificially categorizes his interdisciplinary thought.

Jane Camerini's solution for her slimmer collection is to gather Wallace's writings chronologically. Each section is introduced by a succinct and historically sensitive essay, locating Wallace in his social and political context. She is at pains to show that his spiritualism and socialism were not intellectually anomalous, but were interwoven with his motives and methods for natural history. Where Berry leads the reader from extract to extract, patiently glossing each development in Wallace's thought, Camerini is more inclined to let Wallace's writing speak for itself, allowing the variety of material to suggest its own connections.

One interesting thread thus highlighted is the significance of land in Wallace's life and thought. Time and again it recurs in his writings: his youthful land surveys in Wales; his records of the relationship between the Welsh farming community and the land; the sense of injustice with which he describes the effects of the General Enclosure Act of 1845. In the same period, Wallace records his frustration that a botany book contained no information about plant distribution. Soon after, we see his punctilious mapping of the Amazon; his vital evolutionary connection drawn between phylogeny and distribution; and his socialist writing for the Land Nationalisation Society. Towards the end of his life he was critical of US land use. We also read his children's recollections of their mutual chagrin over 
their father's disregard for 'No trespassing' signs during family walks, and the consequent confrontations with farmers and landowners. This is an instance of how Wallace's science (in this case, what we now refer to as biogeography) was inextricably embedded in his experiences, and within social and political issues. These cannot be removed to leave the 'bare ideas' behind - they simply would not have existed without them.

Wallace's 1858 paper 'On the tendency of varieties to depart infinitely from the original type' was famously read at the same Linnaean Society meeting as Darwin's hastily penned description of natural selection, in a gentlemanly resolution of the question of priority. Infinite Tropics contains more technical papers than The Alfred Russel Wallace Reader, but this one is rightly central to both collections. A close reading of Wallace's paper reveals two interesting differences in emphasis between it and Darwin's writing of the same era.

First, Wallace stressed competition in relation to the environment (whether organic or inorganic) and between species, rather than the interspecific competition, or "ten thousand wedges", which forms a major part of Darwin's On The Origin of Species and has retrospectively been defined as its crucial argument. In this respect, Wallace is more responsible than Darwin for the layperson's understanding of evolutionary factors a struggle against predators rather than against one's fellow-species.

The second difference is that Wallace emphasizes the distinction between domestic and natural varieties. The latter are defined for him by the organism's need for the variant characteristic, its competitive advantage against other varieties, and (in 1858 at least) its strengthening through use. Together these factors produced an irreversible directionality in the genesis of new varieties in nature. Darwin, meanwhile, although he agreed with all these points individually, preferred to stress the similarities between natural and domestic variants in the construction of his argument. Readers were prepared for the idea that nature might select by comparison to the acts of a pigeon breeder, amongst other homely examples. Here, Darwin's version subtly but powerfully altered the reception of his argument, making selection more anthropomorphic and less environmental - less a product of the land, as Wallace would have had it.

The geologist Charles Lyell, the botanist Joseph Hooker and Darwin all failed to pick up on these differences while discussing the presentation of Darwin and Wallace's work as simultaneous discovery. This corroborates the arguments of recent historians (Gillian Beer, Adrian Desmond, James Moore and Robert Young) that Darwin's ideas were by no means as clear-cut as the authors of the 'new synthesis' - and biology textbooks - would have us believe. Wallace's 'problematic' interests and perspectives are revealed by these excellent anthologies (especially Camerini's) to be key to understanding the mid-nineteenthcentury debates about evolution in their true cultural complexity.

Charlotte Sleigh is at the Centre for History and Cultural Studies of Science, Rutherford College, University of Kent at Canterbury, Canterbury CT2 7NX, UK.

\section{I am loved, therefore I think}

\section{The Cradle of Thought: Exploring the Origins of Thinking \\ by Peter Hobson}

Pan Macmillan: 2002. 291 pp. $£ 20$

\section{Simon Baron-Cohen}

How does the mind grow? This is a question that has exercised some of the best minds over the centuries, and Peter Hobson joins this laudable effort to try to answer it with his new book The Cradle of Thought. Hobson is critical of the classical piagetian answer, because it focuses on the child as a solitary mini-scientist, testing his or her current (and usually mistaken) theory in the laboratory of the sand-pit or the playroom. Quite correctly, Hobson points out the limitations of this essentially asocial perspective on cognitive development. Instead, he argues that the origins of all thought lie in social relations.

This line of argument has a long and noble pedigree. Marx suggested that all thought was a product of social and economic relations, and the Russian psychologist Lev Vygotsky (no doubt influenced by his own post-Revolution society) proposed that learning is typically facilitated by one's peer group. But Hobson's slant on the social origins of the mind comes not from this socialist framework so much as his psychoanalytic background.

Sigmund Freud, and later John Bowlby,

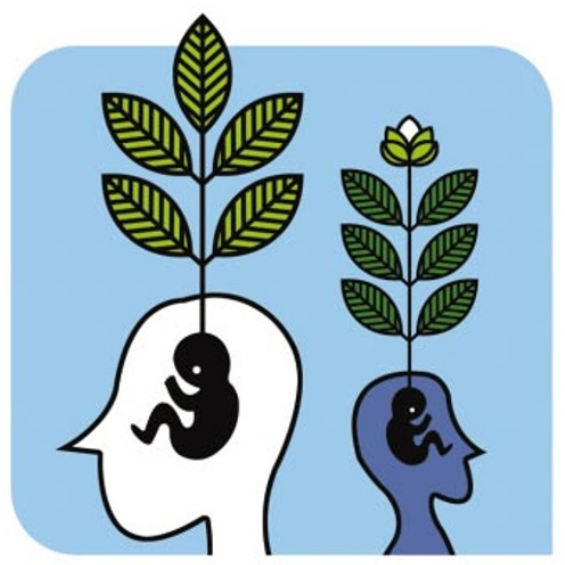

argued convincingly that one's earliest attachments with 'significant others' shape the development of the mind. Usually the 'attachment figure' is an adult caregiver, but - as demonstrated in the famous case of the orphaned Jewish victims of the Nazis studied by Anna Freud - in the absence of a parent figure, attachments can be equally strong towards a peer or sibling.

There is little doubt, from the thousands of experimental studies of the effects of the quality of attachment, that such early relationships are strongly deterministic of later emotional well-being. No one today (if they ever did) now questions whether abuse and neglect are bad for your later mental health - they invariably are. Hobson also reviews the intricate experiments by such pioneer child psychologists as Colwyn Trevarthen and Daniel Stern showing the exquisite sensitivity human infants have to their caregiver's emotional states and behaviour; how the 'dance' between a mother and her infant can become derailed by events such as postnatal depression.

It is not surprising that early emotional factors predict later ones. The surprise from this line of research is that early emotional factors partly predict cognitive outcomes IQ, for example, and school attainment measures such as literacy. Reviewing the large body of evidence leads Hobson to conclude that all the unique aspects of human thought, including our capacity to use symbols, are social in origin.

$\mathrm{He}$ is careful to acknowledge that genetic and neurobiological factors can prevent a child from emotional engagement with others, when discussing children with the psychiatric condition of autism, with whom normal social relations are not possible. But he also reviews studies suggesting that forms of deprivation can also lead to autism, such as the sensory deprivation of congenital blindness or the emotional deprivation of children discovered during the past few years in Romanian orphanages.

There is much to admire in this immensely readable book, and Hobson is both an outstanding scholar and passionate about his subject. His human and clinical concern for people comes through clearly in his writing, and his book will be a welcome contribution to the debate in cognitive development. I part company with him on three fundamental issues, though.

First, just because some aspects of thought (such as empathy) clearly have emotional origins doesn't mean that all human thought is social in origin. How, for example, does an autistic 'savant' who can compute all prime numbers at lightning speed do this with little if any experience of emotional intimacy? This suggests to me that some aspects of cognition have little to do with social relations.

Second, although Hobson acknowledges 